
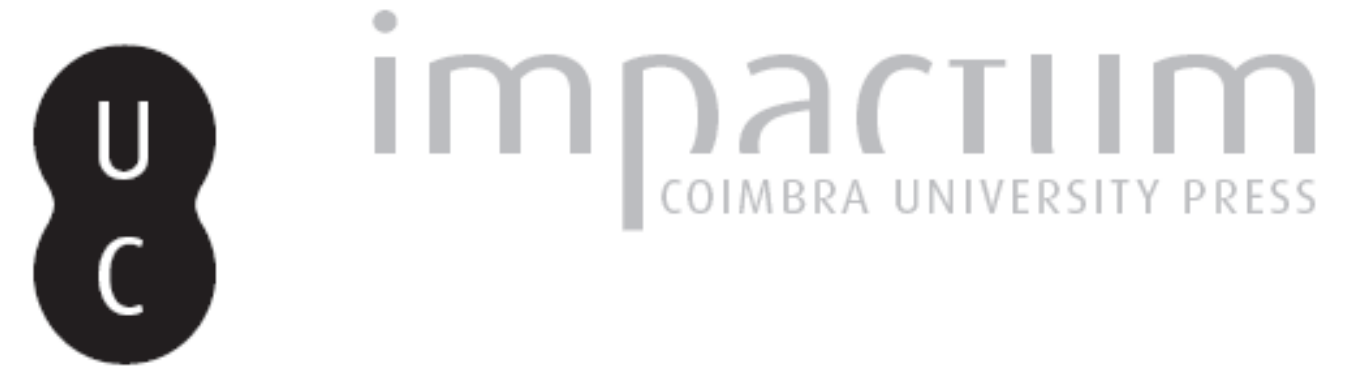

De «patêgos» e «saltins»: itinerância, fronteira e comunidade no circo

Autor(es): $\quad$ Antunes, Maria José Lobo

Publicado por: CIAS - Centro de Investigação em Antropologia e Saúde

URL persistente:

URI:http://hdl.handle.net/10316.2/41274

DOI:

DOI:http://dx.doi.org/10.14195/2182-7982_18_4

Accessed : $\quad$ 26-Apr-2023 12:44:02

A navegação consulta e descarregamento dos títulos inseridos nas Bibliotecas Digitais UC Digitalis, UC Pombalina e UC Impactum, pressupõem a aceitação plena e sem reservas dos Termos e Condições de Uso destas Bibliotecas Digitais, disponíveis em https://digitalis.uc.pt/pt-pt/termos.

Conforme exposto nos referidos Termos e Condições de Uso, o descarregamento de títulos de acesso restrito requer uma licença válida de autorização devendo o utilizador aceder ao(s) documento(s) a partir de um endereço de IP da instituição detentora da supramencionada licença.

Ao utilizador é apenas permitido o descarregamento para uso pessoal, pelo que o emprego do(s) título(s) descarregado(s) para outro fim, designadamente comercial, carece de autorização do respetivo autor ou editor da obra.

Na medida em que todas as obras da UC Digitalis se encontram protegidas pelo Código do Direito de Autor e Direitos Conexos e demais legislação aplicável, toda a cópia, parcial ou total, deste documento, nos casos em que é legalmente admitida, deverá conter ou fazer-se acompanhar por este aviso. 
Antropologia Portuguesa

Volume $18 \cdot 2001$

Departamento de Antropologia | Universidade de Coimbra 


\title{
De «patêgos» e «saltins»: \\ itinerância, fronteira e comunidade no circo'
}

\author{
Maria José Lobo Antunes \\ Centro de Estudos Territoriais, Edificio ISCTE \\ Av. Forças Armadas \\ 1649-026 Lisboa, Portugal \\ zloboantunes@yahoo.com
}

Resumo O que leva o circo a viajar? Mais do que apenas o resultado de um imperativo de sobrevivência ou um elemento performativo central, este artigo propõe que a itinerância das companhias constitui uma forma de vida que se transmite de pais para filhos, num processo de reprodução que articula a organização familiar, a condição profissional e a mobilidade espacial. Seguindo os vários momentos da viagem, procurar-se-á compreender de que forma a itinerância se inscreve nas vidas dos indivíduos, concedendo-lhes uma percepção singular de si mesmos e do mundo em que vivem. No meio circense, onde as fronteiras administrativas são pouco mais do que abstracções sem grande importância, a itinerância constitui o elemento que permite a clara demarcação das fronteiras simbólicas da conunidade.

Palavras-chave Comunidade; circo; itinerância.

Abstract Why is circus itinerant? It is certainly much more than the imperative to survive or a requirement of the performative genre itself. This article proposes that the itinerancy of circus companies is an established way of life, handed down from generation to generation, as a part of reproductive strategy that articulates family organization, professional standing and spatial mobility. By following the various moments within a journey, we shall try to understand the manner through which itinerancy becomes part of the lives of these people, providing

' Este artigo resulta da reformulação de um argumento desenvolvido na minha tese de mestrado (Antunes, 1997). 
them with a unique self-perception and vision of the world in which they travel. In the circus milieu, where administrative frontiers are virtually meaningless abstractions, itinerancy becomes fundamental in clearly delimiting the symbolic frontiers of communities.

Key words Community; circus; itinerancy.

\section{Por que viaja o circo?}

Final de mais uma noite de espectáculo. Enquanto os artistas desaparecem para mudar de roupa, os empregados começam a desmanchar as.bancadas. Ao som metálico da desmontagem, a companhia vai aparecendo lentamente no circo. Algumas mulheres recothem e dobram as cortinas que separam a pista dos bastidores. As raparigas e crianças empilham as cadeiras da plateia e levam-nas para o enorme camião onde cabem todas as coisas de que um espectáculo é feito. Os homens, a quem são deixadas as tarefas mais pesadas, iniciam a lenta coreografia com a qual o circo vai sendo despido: os holofotes e projectores, a bilheteira, as colunas de som, o misterioso emaranhado de cabos, o carrinho das pipocas e algodão doce, vão dando lugar a um espaço cada vez mais vazio, onde se torna dificil reconhecer aquilo que existiu uns minutos antes.

Mais tarde, quando do circo não sobra mais do que a cúpula e as estruturas metálicas que a suportam, inicia-se a maior das tarefas da desmontagem, para a qual todos os homens, artistas e empregados, estāo convocados: a descida do chapiteau. O dono do circo coordena os movimentos e a sua voz sobrepõe-se às dezenas de vozes que ali ecoam. Ao fim de uma hora de esforços, gritos, risos e zangas, o chapiteau desapareceu por completo.

Este momento repete-se uma e outra vez na vida das companhias de circo portuguesas. Entre Janeiro e Outubro, durante a temporada, os circos grandes e médios percorrem as cidades e vilas do pais, a um ritmo que pode oscilar entre uma a duas viagens por semana. Nos meses de Verão seguem a geografia do turismo, parando nas praias de norte a sul de Portugal. Neste período as estadias são mais longas, devido à renovação periódica dos turistas. O fim do Verão marca o início da viagem que os levará ao local escolhido para fazer o Natal e onde permanecerão por mais 
de um mês. Estacionados em grandes centros urbanos, os circos apresentam nesta altura uma versão melhorada do espectáculo que, durante a tournée, caminha pelo país: os terrenos alugados são mais dispendiosos do que os da temporada, as companhias são renovadas com números mais caros e elaborados e aqueles que se mantêm sofrem uma melhoria significativa de salário.

O constante recomeço da viagem pode ser visto como a expressão de um imperativo de sobrevivência: o circo viaja para não morrer, na incessante procura de um público que cada vez menos se interessa pelo espectáculo. Este imperativo tem na sua base os constrangimentos específicos da procura: o circo é um espectáculo largamente previsível, sem grandes novidades e o interesse do público é limitado. Excluindo alguns espectadores mais dedicados, a generalidade não tem por hábito ver os espectáculos das várias companhias: a partir do momento em que se viu um espectáculo, viram-se todos². Por essa razão, o circo não apenas tem de viajar, como também tem de seguir os grandes movimentos dos seus espectadores: durante o Inverno e Primavera, seguem a rota das cidades e vilas; no Verão, deixam-se ficar pelas localidades turisticas; e no Natal, a época em que o público urbano se lembra do circo, aportam nas grandes cidades.

Os constrangimentos especificos da procura do espectáculo de circo determinam uma competição feroz entre as diferentes companhias que circulam no país. Para além da escassez de público, os circos têm de tentar combater a presença das restantes companhias, já que a estadia de um circo numa dada localidade tem como consequência quase inevitável a exaustão do público (Afonso e Antunes, 1999). O sucesso de uns é o insucesso de outros. Se a "tua morte é a minha vida", as situações de cooperação entre as direç̧ões dos circos existem apenas dentro de um conjunto limitado de possibilidades, sendo sujeitas a um cálculo rigoroso por forma a garantir que os beneficios concedidos aos competidores não comprometam o sucesso de quem prestou o auxilio (Afonso e Antunes, 2000; Antunes, 1997).

- Hugues Hotier (1995) analisa um relatório de 1989 sobre as práticas culturais dos franceses, e conclui que a ida ao circo é um acontecimento excepcional: embora $91 \%$ dos inquiridos afirmem ter ido nos doze meses anteriores pelo menos uma vez ao circo, apenas $9 \%$ afirmou ter visto mais do quẽ três espectáculos no mesmo periodo de tempo. 
A explicação económica da itinerância pode ainda ser complementada pela sugestão de Yoram Carmeli (1987) sobre a importância da dimensão performativa da mobilidade dos circos. Segundo este autor, tão relevante quanto a presumivel saturação do público caso as companhias permanecessem por muito tempo na mesma localidade, é o facto de a viagem constituir, em si mesma, uma parte essencial do espectáculo. A chegada dos circos (materializada na clara visibilidade do chapiteau, camiões e caravanas), as estadias limitadas nas diversas terras por onde passam (anunciadas nos cartazes que avisam sobre a partida iminente da companhia), a possibilidade de ver o espectáculo apenas naquele breve tempo, são elementos que constróem o circo como um espectáculo singular, que não partilha o tempo ou espaço das pessoas comuns.

Mais do que a adaptação a constrangimentos económicos específicos (que não apenas condicionam a mobilidade do circo, mas também a investem de uma natureza performativa central), a itinerância constitui para os artistas uma forma de vida que se transmite de pais para filhos, uma herança muitas vezes inescapável: ser artista de circo é viajar de terra em terra e de companhia em companhia. E é precisamente a dimensão experiencial da vida itinerante no meio circense que iremos procurar compreender neste ensaio, analisando a forma pela qual a itinerância se inscreve nas vidas e nas representações dos artistas de circo.

\section{Aprendizagem do circo}

Manhã cedo. A agitação da partida começou. Vozes lá fora, o barulho dos estábulos a serem desmontados, alguns motores de camiões que trabalham. Na luz ainda difusa do dia que começa, toda a companhia está na rua a preparar mais uma viagem. Os homens recolhem as mangueiras da densa teia que distribui água pelas caravanas, enrolam as extensões eléctricas, desenterram as antenas parabólicas. Ouvem-se vozes a chamar os muitos gatos e cães. Alguém que não encontra um animal terá de regressar mais tarde, na esperança de que ele não se perca para sempre. O chapiteau, desmontado na véspera, espera agora no enorme atrelado que o levará dentro de pouco para a próxima terra. 
A preparação da partida pode ser vista como uma epitome do processo que se inicia desde muito cedo na vida dos artistas e cujo primeiro e mais óbvio passo é o da aprendizagem de números e de técnicas de circo. Desde cedo as crianças são iniciadas às muitas tarefas e trabalhos. $\mathrm{Na}$ maioria dos casos, antes de entrarem na escola estão já a ensaiar equilíbrios e acrobacias. Algumas fazem-no por curiosidade, tentando imitar o pai ou a mãe. Mas nem sempre os ensaios são motivados por uma curiosidade natural. Em alguns casos eles são uma obrigação inelutável: os pais determinam o que os filhos devem fazer e estabelecem uma disciplina rígida à qual dificilmente se pode fugir. Tommy M., um dos palhaços contratados no Circo Chen na temporada de 96 , começou a ensaiar muito cedo com o seu pai, um rigoroso treinador guiado por infindáveis ideias para truques e números novos. Tommy lembra a disciplina férrea que o fazia levantar da cama com os seus irmãos quando o dia ainda não tinha nascido e os levava para horas de intenso treino. $O$ pai parecia nunca estar satisfeito. Os truques eram repetidos até à exaustão ao ritmo das ordens paternas. Pendurados no "bambu" atado numa árvore, Tommy e os seus irmãos ensaiavam os truques inventados pelo pai tentando seguir a rapidez quase impraticável que lhes era exigida. A disciplina dos ensaios era mantida pela autoridade e pela força, mais do que pela dedicação espontânea à arte; ela resultava de uma estranha combinação de medo e obediência incondicional:

Quando o meu pai nos vinha acordar para ir ensaiar, eu nunca me levantava de bom gosto, porque eu sabia que se fizesse bem ou fizesse mal, havia momentos que eu levava à mesma! Por uma coisa ou por outra, havia dias que levava sempre porrada. Naquela altura não se podia ter gostos, não se podia dizer «eu quero fazer aquilo». O meu pai dizia «tu fazes aquilo» e fazes mesmo. Era ditadura! Era como todo o mundo vivia.

Apesar deste relato se situar a décadas de distância da actualidade, a situação não parece ter-se alterado de uma forma significativa. Os pais continuam a ensaiar os filhos, que se submetem de uma forma mais ou menos definitiva à vontade paterna. Pouco depois da nossa chegada ao Circo assistimos, surpreendidas, a um duro ensaio nocturno de Golias, um jovem equilibrista de dezoito anos. $O$ barulho de vozes dentro do chapiteau depois do espectáculo levou-nos a espreitar o que se passava. $\mathrm{Na}$ meia luz do circo vazio, o pai obrigava Golias a ensaiar. No alto da mesa 
onde faz o número de equilíbrio em rolos, o ar perdido de Golias - uma mistura de obediência, medo e zanga - faziam-no parecer uma criança de cinco anos. Cá em baixo, o pai gritava irritado, olhando os erros que o filho cometia. Um ensaio rigoroso e agressivo, por vezes quase humilhante, em que Golias foi forçado a conter as lágrimas e a repisar os seus erros. Só passara um mês desde a nossa chegada ao Circo Chen, e esta cena chocou-nos pela brutalidade. Mais tarde viríamos a perceber que o que julgáramos brutal era, afinal, um episódio absolutamente comum. Situações como esta são esperadas e mesmo desejáveis, pois reflectem a preocupação e brio profissional dos pais que procuram aperfeiçoar os pequenos erros e deslizes técnicos dos filhos. No circo, o exercício da paternidade implica o exercício da disciplina.

Ao mesmo tempo que ensaiam truques e números, as crianças começam a ir à escola. A escolaridade é geralmente cumprida de terra em terra, com a autorização de uma guia de transferência passada pelo Ministério da Educação que lhes permite entrar e sair das escolas ao ritmo da itinerância. $O$ insucesso escolar e a desmotivação são grandes. Se, por um lado, os pais não estimulam o estudo e o interesse das crianças pelo que lhes é ensinado nem tampouco os obrigam a continuar, por outro lado a descontinuidade da aprendizagem (diferentes escolas, professores e métodos de ensino) cria quase inevitavelmente alguns problemas de adaptação. Quando as crianças de circo vão à escola, cumprem apenas e na melhor das hipóteses a escolaridade obrigatória ${ }^{3}$. Crescem quase sem habilitações, pequenos artistas que ensaiam e treinam para conseguirem um número que lhes garanta bons contratos e bons ordenados. Dos muitos casos que conhecemos, nenhum pai exigiu do filho mais do que poucos anos de escola; estes anos servem para aprender a ler e escrever, o que Ihes permitirá tirar a carta de condução e, eventualmente, aprender um pouco de inglês.

${ }^{3}$ De acordo com uma investigação desenvolvida a pedido do Departamento de Ensino Básico do Ministério da Educação sobre as necessidades educativas da população circense portuguesa, num universo de 139 individuos distribuidos por sete companhias de circo $56 \%$ tinham cumprido apenas o $4^{\circ}$ ano de escolaridade. Das dezoito crianças em idade escolar (6-16 anos), apenas oito frequentavam a escola; as restantes dez representavam casos de abandono escolar após a conclusão do $4^{\circ}$ ano (Afonso e Antunes, 1999). 
Mais importante do que estudar é saber trabalhar no circo. E, para isso, quase todos estão habilitados. A melhor maneira de ensinar as crianças a serem artistas de circo é através de uma iniciação precoce. A maioria dos indivíduos tem como primeira experiência algumas pequenas entradas sem grande dificuldade em números cómicos; os outros estreiam-se na vida do circo com números mais exigentes ou elaborados (contorcionismo, trapézio, arame). Apesar dos primeiros passos no circo poderem não ser muito memoráveis ou desejados (eles não são mais do começo daquilo que está ainda por acontecer), as pessoas prosseguem a aprendizagem que os irá levar a serem artistas de pleno direito. Até à idade de quinze anos, todos os jovens já têm o seu percurso artístico traçado, dado que a iniciação das crianças na vida profissional é tida como um bem económico fundamental e uma garantia de subsistência das familias.

A organização familiar do trabalho torna ainda mais intenso o processo pelo qual as pessoas inscrevem as suas vidas nesta comunidade singular. Nos primeiros anos de vida, são os pais quem escolhe os números com que os filhos irão trabalhar e os ensaiam até que estejam prontos para estrear. Assim sendo, a reprodução de números no interior das familias é bastante comum: existem famílias de palhaços, familias de acrobatas, familias de equilibristas. Enquanto vivem com os pais, os artistas solteiros fazem parte dos números familiares em que a presença de várias pessoas é requerida. Para efeitos de contratação, a família funciona como uma unidade de interdependências, em que a colaboração de todos os elementos é indispensável e em que o trabalho de alguns é tomado como o trabalho de todos: o dinheiro pertence à familia e não àquele que o ganhou.

A dependência económica no interior das familias é um elemento característico do circo, tanto entre os artistas contratados como entre os que detêm a propriedade de circos (Afonso e Antunes, 2000). Em ambos os casos, o trabalho dos filhos solteiros não é remunerado, fazendo parte do fundo de subsistência comum da familia. No entanto, as famílias proprietárias de circos parecem levar esta lógica ainda mais longe, justificando a reduzida autonomia económica dos filhos com a construção e preservação de uma propriedade que um dia será sua. O princípio subjacente a esta prática generalizada é o de que, ainda que não recebam salários, os filhos estão a trabalhar para algo que lhes pertence. A compensação monetária imediata é substituída por um vínculo que, a longo ou médio 
prazo, lhes poderá trazer maiores beneficios do que o mero pagamento de um salário: a transmissão de um património valioso (o alvará e o material do circo) e do poder decisório efectivo (a direcção da companhia).

As pessoas nascem e crescem em famílias de circo e desde pequenas são ensinadas a sobreviver com os instrumentos que possuem, isto é, seguindo também elas o caminho percorrido pelos pais, tornando-se artistas de circo. Esta quase prisão, este vínculo indelével que marca as vidas das pessoas, começa muito cedo e resulta de uma combinação de circunstâncias que se repetem em todos e cada um dos casos. Se, num primeiro momento, os filhos dependem dos pais e da sua vontade (e por isso aprendem números, saem cedo à pista e não são obrigadas a estudar mais do que alguns anos), mais tarde também os pais irão depender dos filhos para sobreviverem. Ao investirem preferencialmente na aprendizagem circense das crianças, os artistas estão a garantir o seu sustento, dado que os salários dos fillhos solteiros pertencem à família. Por outro lado, ao negligenciarem a escolarização das crianças, estão forçosamente a reduzir as alternativas profissionais fora do circo. A eventual vontade de deixar este mundo depara-se com as muitas dificuldades geradas pela inexistência de habilitações que assegurem um emprego que lhes permita viver.

Podemos, assim, compreender que a itinerância, a aprendizagem precoce das técnicas circenses e a organização familiar do trabalho constituem os elementos centrais do processo de reprodução social do circo. Através deste processo, as pessoas reeditam a sua vida nos filhos e, com ela, o circo enquanto forma de vida particular. Este processo de reprodução do circo aproxima-se da ideia de "orquestração sem maestro" presente no conceito de habitus desenvolvido por Pierre Bourdieu, pela qual as práticas individuais e colectivas contêm em si mesmas os princípios estruturadores que permitem a sua regeneração. $O$ sistema de disposições que compõem o habitus constitui " $(. .$.$) a past which survives in the present$ and tends to perpetuate itself into the future by making itself present in practices structured according to its principles (...)" (Bourdieu, 1977: 82).

\section{A viagem como fronteira}

A caravana do circo está de novo a caminho. À frente segue o director da companhia com o enorme camião que é a sua casa. Atrás 
de si, desfilam pela estrada dezenas de camiões, carrinhas e roulottes, numa lentidão que impacienta todos os que se cruzam com este estranho cortejo. Um artista que pára na berma com um problema mecânico e outro que encosta para ajudar, seguindo a regra do circo da solidariedade em viagem. Parados na estrada, gesticulam para que a caravana prossiga. E ela continua, arrastada e ruidosa, gastando os poucos quilómetros que a separam da próxima terra.

A mobilidade em que os artistas de circo vivem condiciona uma visão muito particular da geografia e das suas fronteiras. Se, por um lado, as temporadas e os contratos os levam a percorrer várias terras e países diferentes, por outro lado nas companhias (e mesmo nas famílias) entrecruzam-se pessoas de nacionalidades diversas, sem que isso pareça constituir um problema no entendimento mútuo. Esta multinacionalidade e constante movimento dilui a importância das fronteiras nacionais, que se tornam linhas ténues ou mesmo irrelevantes. No entanto, há uma fronteira que todos os artistas de circo reconhecem como fundamental: é aquela que separa os que 'são de circo' dos que não o são, e que divide dois mundos que consideram ser radicalmente distintos. E é precisamente esta fronteira que serve de suporte aos discursos sobre si mesmos e sobre a sua convivência com os outros.

De acordo com os artistas de circo, o que os distingue das demais pessoas é a itinerância, que os leva a conhecer os mais improváveis sítios do mundo. Quando questionados sobre o que os leva a viajar, os artistas respondem que a itinerância lhes "está no sangue", porque não conseguem sequer conceber uma forma de vida que os prendesse a um qualquer sítio durante muito tempo ${ }^{4}$. Os outros, os que não nasceram no circo, são "patêgos". Este termo encerra uma conotação depreciativa óbvia: aquele que não percebe nada, alguém que é facilmente enganado. Alguns artistas mostravam um claro desconforto quando se apercebiam do nosso conhecimento do termo - as "patêgas" que sabiam ser "patêgas" e, portanto, compreendiam a ideia depreciativa implícita. Quando eram confrontados com esta situação, apressavam-se a tentar justificar o seu sentido - ou

${ }^{4}$ A itinerância é representada de uma forma semelhante pelos ciganos, como uma característica que está inscrita no seu "sangue", situando-se ao nível de uma imposição existencial herdada (Liégeois, 1971; Okely, 1983). 
mesmo a atribuir-lhe um outro sentido. Quando finalmente se habituaram ao conhecimento que tínhamos da nossa condição de "patêgas", a necessidade de encontrar justificações deixou de existir até que, nos tempos finais, perante a nossa familiarização com a vida de circo, as familias e as pessoas, fomos informadas de que já não éramos "patêgas". Não éramos, nem nunca seríamos "saltins", mas éramos pelo menos umas "patêgas" iluminadas.

O termo "patêgo" não é o resultado de uma escolha ingénua; reflectindo a ideia que a maioria dos artistas de circo têm das pessoas que não nasceram no circo. Os "patêgos" vivem sempre no mesmo sítio, com as mesmas pessoas, a fazer o mesmo trabalho. Têm horários a cumprir, viajam pouco e conhecem mal o mundo que os rodeia. Vêem apenas o que está à frente do seu nariz e não conseguem imaginar que, para além dele, existe um mundo enorme. Os "patêgos" vão ao circo e, no entanto, não entendem o que está à sua frente: gostam de números que não têm dificuldade nenhuma, ignoram outros que são verdadeiramente bons, são enganados por espectáculos que se afirmam de circo e não o sāo. Por todas estas razões, são "patêgos".

A itinerância é utilizada não somente para estabelecer a fronteira do grupo (os de circo viajam, os que não são de circo estão parados), mas também para valorizar a sua auto-imagem, dado que permite contornar habilmente a questão da fraca escolaridade que os poderia colocar numa posição de desvantagem. Este é, aliás, um tema recorrente de conversa, em que o consenso se estabelece facilmente: apesar de terem "poucos estudos", apesar de alguns não saberem mesmo ler ou escrever, os artistas de circo afirmam ter uma maior abertura e mais profundo conhecimento do mundo. Como nos disse um empresário, "as pessoas da vila são mais evoluídas do que as da aldeia; as da cidade são mais evoluidas do que as da vila; e as pessoas de circo são ainda mais evoluidas, porque viajam muito e vêem muita coisa". O que poderia ser encarado como uma causa de marginalidade e um entrave à aprendizagem formal, é transformado numa fonte de conhecimento inesgotável a que a maioria das pessoas não tem acesso.

Existe um outro elemento que simultaneamente une os artistas e os distancia dos "patêgos", ao conceder a possibilidade de se expressarem sem serem compreendidos: o "calão" de circo. Embora seja referida no meio como "calão", esta linguagem é na realidade uma gíria, no sentido 
em que constitui o vocabulário peculiar de um grupo profissional que partilha a mesma condição social. $O$ "calão" de circo não abarca todo o campo da língua: ele não apresenta uma sintaxe original, encontrando-se reduzido a um léxico que se limita aos centros de interesse do meio circense. A gíria de circo inclui termos técnicos referentes ao espectáculo, ao seu planeamento e organização, alguns deles derivados do italiano ("antenas" ou "fónica"), francês ("chapiteau" ou "ruta") ou espanhol ("charibari" ou "passa-calle"). Mas a gíria estende-se para além dos limites do vocabulário meramente técnico: o seu léxico engloba ainda expressões de uso corrente, cuja utilização tem como objectivo fundamental a manutenção da privacidade do grupo.

No outro lado da fronteira invisivel da qual os "patêgos" estão excluídos, encontram-se todos aqueles que nasceram no circo e dele fazem a sua vida: os "saltins". Ao mesmo tempo que estabelecem as diferenças que os separam dos "patêgos", os artistas de circo reconhecem as semeIhanças que os unem a todos aqueles que fazem do circo o seu modo de vida. São unânimes em considerar que existe uma "maneira de ser e de pensar" comum a todos os "saltins", uma "mentalidade" particular que se transmite de pais para filhos. No entanto, sempre que tentámos perceber em que se traduzia esta "mentalidade", pouco mais recebemos do que respostas vagas que repetiam a centralidade da itinerância e das suas consequências nas vidas das pessoas. Quando, numa conversa, pedimos ao director do circo que explicasse este enunciado um pouco vago, ele utilizou como termo de comparação os ciganos - de cuja inagem, noutras circunstâncias, se procuram afastar:

$\mathrm{O}$ circo é quase como as etnias. Por que é que os ciganos que nasceram já em Portugal de há 500,600, 200 anos, continuam a ter uma mentalidade diferente? Porque essa etnia tem um círculo restrito. E o circo é igual! Aunque se nós vivemos num meio ambiente, no meio de pessoal, na nossa vida particular vivemos numa pequena comunidade. E então o que é que passa? Os nossos actos são muito semelhantes. Depois há uma diferença, mas a diferença está naquele que teve um bocado de instrução ou daquele que não a teve. Mas isso passa também nos ciganos: há ciganos advogados, ciganos doutores. Mas a sua mentalidade não é igual à das pessoas de fora. Ele tem sempre, fica sempre, com uma coisa importante, que é a nossa genética, que é o nosso sangue. 
Esta explicação, mais elaborada do que a maioria, apresenta os artistas de circo como um conjunto de pessoas que, apesar de viverem num meio social mais vasto, se encontram encerradas no interior da sua "pequena comunidade". As suas representações ("mentalidade") e as suas práticas ("actos") são, por isso, muito semelhantes. Esta herança cultural, este modo de ser e de viver, é transmitido de pais para filhos. A natureza inescapável desta condição é explicada pelo facto de esta pertença ser mais do que uma escolha; ela reflecte um dado inato, algo que 'está no sangue' dos artistas e que constitui o seu património 'genético' - é-se de circo porque se nasceu no meio.

Este vínculo indelével que marca as vidas das pessoas, toma um carácter de urgência que, noutros contextos, se poderia encontrar diluído. Não se "é de circo" porque se tenha escolhido sê-lo, mas porque se nasceu neste meio. Mesmo que se deseje deixar de fazer parte da comunidade, torna-se dificil apagar os laços que fazem desta pertença um elo quase inquebrável. São muitas as histórias contadas sobre esta pertença mais forte do que a vontade: "saltins" que, mesmo conseguindo uma situação estável e confortável fora do circo, vivem com a saudade do que eram antes da partida; ou ainda, histórias de artistas que resolvem sair da vida de circo mas acabam por regressar, vencidos pela constatação da impossibilidade de abandono. Florinda T., lembra desta maneira os primeiros tempos do seu afastamento do circo:

Quando eu casei, casei fora do circo. Passado um mês e picos fui vìsitar os meus pais, que estavam na praia da Póvoa de Varzim. Entro. Hora do espectáculo. Comecei logo a respirar outro oxigénio! Fui para a primeira fila ver o espectáculo. Quando começo a ver a minha mãe e o meu irmão, e eu não estava lá; quando começo a ver o meu pai, os meus tios e os meus primos, e eu não estava lá, coisas que eu estava a fazer com eles... Não me contive. Comecei para ali a chorar, parecia que estava a ver um drama do século passado. Ao passo que as pessoas que são, por exemplo, empregadas de escritório ou outra profissão qualquer, não desatam a chorar quando vêem outro empregado de escritório a trabalhar!

De facto, se há algo que caracteriza o circo é o facto de este ser muito mais do que uma profissão. Ao contrário das sociedades urbanas contemporâneas, em que os diversos contextos de interacção se encontram disso- 
ciados, neste meio concentram-se e condensam-se relações de trabalho, de parentesco, de amizade e de vizinhança. O tempo do trabalho é também o tempo da família, o tempo dos amigos, ou o tempo das conversas de circunstância. O circo é, por isso, o palco quase exclusivo de todas as sociabilidades dos "saltins", o local onde as relações emocionalmente significativas convergem, concedendo ao sentido de pertença uma intensidade singular. Deixar o circo não é apenas abandonar uma profissāo: é mergulhar num mundo absolutamente novo, cujas regras e personagens se desconhecem.

Se, num primeiro olhar, a itinerância se apresenta como o resultado de um imperativo de sobrevivência (o circo viaja para não morrer), ela constitui-se também como o elemento fundamental para a construção da identidade social dos "saltins", ao estabelecer a fronteira da comunidade. Utilizamos aqui o termo fronteira no sentido processual e relacional proposto por Fredrik Barth (1969) e Anthony Cohen (1985): fronteiras sociais investidas de um carácter simbólico, que permitem o reconhecimento dos limites da comunidade e a "dicotomização dos outros como estranhos" (Barth, 1969: 204), a quem está intrinsecamente vedado o acesso à experiência de se "ser de circo".

O reconhecimento da distintividade social do circo enquanto comunidade permite a construção de um conjunto de discursos que inscrevem a identidade dos "saltins" num nível de pertença anterior à vontade (a "genética" ou o "sangue"), manifestando-se em formas de pensar e agir alegadamente distintas das demais. Estes discursos encontram o seu suporte numa visão essencialista da condição itinerante dos artistas de circo - a viagem está-lhes no sangue e é algo que se entranha nas pessoas e as impele a regressar uma e outra vez apesar das tentativas de abandono.

O conjunto de qualidades indefiniveis que constituem a experiência de "ser de circo", traduzem aquilo a que Anthony P. Cohen (1985) se refere como o "sentido da primazia da pertença". Mais do que qualquer outra categoria a que se possa pertencer (português, espanhol, homem, mulher), "é-se" de circo - isto é, pertence-se a uma comunidade itinerante, na qual as únicas fronteiras que têm uma existência real e determinante são as que a separam do mundo exterior. E é através de um processo relacional, de oposição a todos os que não nasceram no circo e que não têm a viagem "no sangue", que os "saltins" constróem a sua imagem: uma imagem onde a itinerância, a família e a condição profissional se impli- 
cam reciprocamente, desenhando um círculo cujo início e fim são dificeis de definir.

\section{Itinerância e marginalidade}

Depois de uma indiscreta entrada na terra, a caravana do circo chega finalmente ao novo destino. Uma nuvem de fumo paira no terreno, todos os motores trabalham num compasso de espera. $\mathrm{O}$ director do circo olha em volta, vagueia e mede o espaço, desenhando a paisagem temporária que dentro de horas se erguerá ali. As mulheres e crianças vão gastar o tempo para o café mais próximo. Nos olhares de todos os que passam, os "saltins" descobrem o misto de desconfiança, medo e curiosidade que sempre revêem nos "patêgos", e que encerra os artistas na solidão de um mundo desconhecido.

A delimitação da fronteira que separa os artistas de circo do exterior não os torna invulneráveis a equivocos e mal-entendidos. Apesar de viverem num mundo relativamente fechado, conhecem as imagens negativas que os rodeiam, enviando-os para uma zona sombria da qual não conseguem sair. Os discursos sobre si e a sua relação com os outros remetem para a marginalização de que se sentem alvo. Referem com mágoa o esquecimento a que dizem ser votados pelas estruturas institucionais e pelos meios de comunicação, que os preterem em favor de outras formas de entretenimento esquecendo que "o circo também é cultura". A inexistência de subsídios oficiais, a inoperacionalidade dos sindicatos e a hostilidade do poder local contribuem largamente para a frágil sobrevivência destas empresas familiares. Por outro lado, sentem-se encarados com desconfiança e queixam-se da ignorância e das histórias que os rodeiam e que os obrigam a manterem-se distantes dos olhares curiosos que os espreitam para lá do círculo que montam à volta do chapiteau.

Um dos maiores equivocos em que os artistas de circo afirmam estar envoltos é aquele que os aproxima dos ciganos. Esta situação é vista como o resultado da já antiga e inevitável jgnorância dos "patêgos", que teimam em confundir realidades diversas só porque apresentam uma caracteristica comum. Para além da itinerância, não reconhecem qualquer semeIhança com os ciganos. Segundo nos disseram, o elemento que desde logo 
torna estes dois grupos imiscíveis é a natureza das ocupações: os ciganos são "mercadores" e as pessoas que nasceram no circo são "artistas". No entanto, este equívoco persiste em manifestações difusas, onde a suspeição e o medo tornam ainda mais presente e intransponivel a fronteira que os separa do exteriors.

A maior visibilidade dos ciganos teve como consequência óbvia a associação imediata de qualquer grupo itinerante a esta etnia, bem como a aplicação arbitrária de um tratamento indiferenciadamente hostil. Os argumentos utilizados no controle social dos itinerantes (ciganos e não ciganos) basearam-se desde o início num complexo conjunto de ideias de criminalidade, vagabundagem, amoralidade e paganismo, racionalidade económica e a tentativa de imposição de padrões minimos de saúde e educação (Liégeois, 1985). O carácter discricionário das medidas repressivas tomadas no passado" foi substituído pela manipulação de noções como "salubridade e higiene pública", "proteç̧ão dos espaços e ambiente" ou "ordem e tranquilidade pública" que, na época contemporânea, constituem o fundamento legal dos regulamentos aplicáveis à passagem e permanência das populações itinerantes nas várias localidades (Liégeois, 1985).

Por outro lado, a exploração de recursos e oportunidades económicas periféricas (nenhum dos bens ou serviços prestados é indispensável), e a recusa de integração no mercado de trabalho convencional (as activi-

${ }^{3} \mathrm{O}$ equivoco com os ciganos não é recente. O tempo dos primeiros registos do aparecimento desta etnia na Europa entre os séculos XIV e XV (Machado, 1988) é também o tempo que marca a assimilação das populaçōes itinerantes autóctones aos ciganos, cuja maior proeminēncia lhes concedia uma posição de destaque no conjunto impreciso de individuos cuja forma de vida assenta na mobilidade geográfica. O presumivel perigo dos ciganos, decorrente da conjugaçāo de diversos atributos profundamente negativos, tornousse a única realidade perceptivel, que rapidamente se estendeu a todos os grupos itinerantes, ciganos e não-ciganos. Este conhecimento feito de equivocos chegou mesmo a ser corroborado por trabalhos de natureza cientifica; Ian Hancock menciona algumas investigações na área da linguística que, durante mais de cinquenta anos, difundiram a tese de que palavras como "posse" ou "dever" não existiam no dialecto Romano (Hancock, 1988; 1997). Estas afirmações, envoltas numa suposta cjentificidade, legitimaram as vozes que acusavam os ciganos de serem intrinsecamente desonestos e moralmente criticáveis.

"Durante anos, foi comum a aplicação de penas como a condenação à morte, os trabalhos forçados, o exílio ou as "caçadas ao cigano" - aliảs, o ủltimo registo de uma "caçada ao cigano" na Dinamarca data de 1835 (Liégeois, 1985; Mayall, 1988). 
dades desenvolvidas assumem a forma de auto-emprego, em que a familia desempenha um papel essencial), sublinham as diferenças que separam as populações itinerantes das restantes pessoas. É neste sentido que Sharon B. Gmelch (1986) introduz o termo "subculturas ocupacionais periféricas": se, por um lado, as profissões itinerantes estão excluídas das estruturas formais do mercado de trabalho convencional, por outro, os individuos que as exercem constituem grupos relativamente fechados com discursos identitários marcados.

De certa forma, é como se a mobilidade espacial traduzisse uma recusa implícita de aceitação das regras do jogo que estipula a permanência e a sedentarização como requisitos fundamentais. É, pois, natural que o estigma do vagabundo ou do indigente se cole à pele desta categoria de indivíduos economicamente marginais e socialmente desintegrados. Utilizamos o termo estigma tal como foi desenvolvido por Erving Goffman: um atributo profundamente negativo que decorre do desajustamento entre a identidade social virtual e real, e cuja principal consequência é o descrédito dos individuos ou grupos a quem se encontra associado. "By definition (...) we believe the person with the stigma is not quite human. On this assumption we exercise varieties of discrimination through which we effectively, if often unthinkingly, reduce his life chances. We construct a stigma theory, an ideology to explain his inferiority and account for the danger he represents, sometimes rationalizing an animosity based on differences (...)" (Goffman, 1963: 15).

Conscientes dos equívocos que os envolvem, os artistas de circo tentam gerir a imagem negativa que não reconhecem como verdadeira. $\mathrm{O}$ primeiro passo dado neste sentido é o de deslocar os atributos negativos para outros indivíduos ou grupos. João de Pina Cabral e Nelson Lourenço referem uma estratégia semelhante na gestão da marginalidade dos macaenses, através da transferência dos preconceitos étnicos que se thes aplicam para outrém, procedendo ao que os autores denominam de "dinâmica do desprezo" (Cabral e Lourenço, 1993: 163). É assim que, num primeiro momento, os artistas de circo se distanciam dos ciganos (os "mercadores") ao reafirmarem a sua identidade de "artistas": para se ser artista de circo é necessário não apenas nascer no meio, mas também e sobretudo ter amor à arte e um espírito de sacrificio que permita aguentar as muitas dificuldades desta forma de vida. A identificação destes atributos positivos e presumivelmente imprescindíveis na formação de um 
"artista" permite a passagem para o segundo momento da transferência dos elementos negativos, desta vez no interior do mejo circense através da delimitação de uma segunda fronteira que separa os verdadeiros artistas (aqueles que possuem estes atributos) e aqueles que não os possuem.

O termo "saltin", forma abreviada de "saltimbanco", encerra um duplo sentido: por um lado, designa a generalidade dos artistas de circo; por outro lado, é utilizado para estabelecer uma distinção no interior da comunidade circense. Apesar de qualquer artista de circo ser "saltin" no primeiro e mais abrangente sentido da palavra, todos são unânimes em afastar para terceiros a carga pejorativa que lhe está associada. $O$ outro sentido do termo "saltin" serve para designar os "artistas de $3^{\mathrm{a}}$ ou $4^{\text {al }}$ categoria", sem qualquer brio ou dignidade profissional. Por vezes, o segundo sentido do termo "saltin" constitui um sinónimo de "pialgateiros": indivíduos que ganham a vida em "pialgatas", imitações pobres de espectáculos de circo levadas a cabo em locais considerados impróprios como cafés e escolas, ou mesmo na rua.

O retrato deste segundo sentido de "saltin" recorre a um conjunto impreciso de características negativas que, com algumas variações menores, reenviam para ideias como a falta de profissionalismo ou a tendência para a arruaça. Ou seja, não é apenas na "pialgata" que se encontram "saltins"; alguns de entre eles podem ser também encontrados nos circos, fazendo-se passar por algo que realmente não são. Noelia C., filha do director do Circo Chen e uma das mais inflamadas críticas dos "saltins", atribui-lhes a responsabilidade da má imagem do circo e da falta de qualidade dos números por eles apresentados:

Os saltins são também artistas de circo, mas para mim não são artistas de circo. São saltins porque não sabem estar na pista, pouco thes importa se fazem bem ou se fazem mal, não querem o progresso no que estão a fazer, estreiam assim e morrem assim. Estreiam a fazer malabares e morrem assim, não vão mais para a frente, estreiam o primeiro fato e toda a vida vão usar esse fato, a música do número é sempre a mesma. Aqui em Portugal vês malabaristas ou outros artistas sempre com as mesmas músicas e o mesmo vestuário. Eles não sabem estar na pista, não sabem ser artistas. Eu também não me julgo uma atracção, mas tento imitar uma coisa que faça ver que na pista estou eu! Para mim há essa diferença: saltin, artista e atracção. Sempre. Para mim são diferentes todos. E tu percebes quando é uma atracção. 
Nos "saltins", o brio profissional é substituido por uma inércia generalizada; desde que consigam contratos e garantam a subsistência imediata, nada os motiva a procurar a perfeição. Por seu turno, o artista de circo ("saltin" no primeiro, mas não no segundo sentido), encara o seu trabalho com um rigor irrepreensivel. Mas o artista de circo não se faz apenas com trabalho e sacrificio; em larga medida, ele é o resultado de um conjunto de qualidades indefiníveis que permitem a sua distinção imediata de um qualquer executante perfeccionista. Ele "sabe estar na pista", sabe agradar ao público mesmo quando não tem um número de grande dificuldade, pois emana um brilho que nada consegue apagar.

O carácter vago dos elementos que identificam os "saltins" permite múltiplas interpretações e uma aplicação arbitrária e estratégica nas rivalidades entre pessoas e famílias de circo. Se se perguntasse a cada um deles quem incluiriam dentro desta categoria, provavelmente obter-se-ia tantas respostas diferentes quantas as questões colocadas. Todos os artistas admitem a existência de "saltins" - indivíduos pouco sérios e pouco profissionais, que mancham a reputação do meio e do espectáculo. No entanto, nenhum deles se reconhece como tal: "saltins" são sempre e inevitavelmente os outros, aqueles que por várias razões prescindiram do orgulho de serem verdadeiros artistas.

A imagem que os artistas de circo constróem de si mesmos com o intuito de anular os estereótipos que os cercam não vem pôr em causa os valores hegemónicos que os colocam à margem. Pelo contrário, os seus discursos encontram-se enredados nas malhas do discurso dominante e os argumentos de valorização da identidade do grupo estão ancorados nos "aspectos diurnos" da vida social. Ao demarcarem a distância que os separa dos ciganos e dos "saltins", ao sublinharem a importância de qualidades como a rectidão e a honestidade, os artistas de circo estão a propor um discurso que se situa nos "interstícios do mundo convencional", já que parecem ser incapazes de elaborar uma verdadeira alternativa ao valores hegemónicos da sua cultura (Cabral, 2000). Deparamo-nos, assim, com uma estranha ironia: embora se esforcem por demonstrar a sua diferença e o seu carácter único, fazem-no utilizando os argumentos dos quais se pretendem distanciar, ficando presos à lógica que pretendem refutar. 


\section{Circo e comunidade}

As caravanas estão todas arrumadas. A bilheteira ocupa o lugar dianteiro, a entrada pela qual o público surgirá no dia seguinte. Nos estábulos, já erguidos, recomeçou o intenso movimento em torno dos cavalos. Pequenos grupos de artistas percorrem as ruas em volta, em expedições de reconhecimento da terra e do que nela existe. Resta agora montar o chapiteau, prova indesmentível de que o circo chegou à cidade, para mais uns fugazes dias de espectáculo.

Em que sentido pode o circo ser visto como uma comunidade? A presente discussão segue a linha argumentativa que privilegia a fluidez da ideia de comunidade, deslocando a atenção para os processos pelos quais as suas fronteiras são apreendidas, construídas e mantidas. De acordo com este olhar, o que define uma comunidade não é a existência de fronteiras estruturais alegadamente inequivocas (língua, território, religião, etc), mas sim a construção e reconhecimento de fronteiras simbólicas. Esta perspectiva analítica, ancorada no trabalho de Barth (1969) e Cohen (1985), propõe a conceptualização da comunidade como o resultado de um processo relacional, através do qual a comunidade é imaginada e representada pelos seus membros como constituindo uma realidade social singular, por oposição a outras entidades contrastantes. Nas palavras de Cohen (1985: 98) "Community exists in the minds of its members, and should not be confused with geographic or sociographic assertions of 'fact'. By extension, the distinctiveness of communities and, thus, the reality of their boundaries, similarly lies in the mind, in the meanings which people attach to them, not in their structural forms." Neste sentido, o circo constitui sem dúvida uma comunidade.

Por outro lado, Fredrik Barth salienta o papel das fronteiras como elementos que permitem canalizar a vida social, ao implicarem uma organização complexa das relações sociais. A identificação de outra pessoa como membro da mesma comunidade permite um "potencial de diversificação e expansão da relação social que poderá cobrir todos os sectores e domínios de actividade". Pelo contrário, a "dicotomização dos outros enquanto estranhos" implica a restrição da interacção a dominios de entendimento comum e interesse mútuo (Barth, 1969: 204). Artistas e empresários, conceben-se a si mesmos como "saltins", afirmando repeti- 
damente as diferenças que os separam dos "patêgos". Os discursos essencialistas sobre a pertença a esta comunidade como algo que está inscrito no "sangue", fortalecem as fronteiras no interior das quais toda a vida social dos individuos é condensada. Nascer no circo não é, assim, um mero dado biográfico. As suas consequências não são apenas práticas e concretas (nasce-se no circo, trabalha-se como artista, casa-se e vive-se neste meio); elas estendem-se para além do imediatismo da vida quotidiana, implicando uma percepção singular de si mesmo e do(s) mundo(s) em que se vive.

Para além de constituir uma fronteira simbólica fundamental, a itinerância surge também como uma fronteira estrutural: a liberdade de movimentos associada à mobilidade implica, ao mesmo tempo, os princípios que negam essa liberdade. Os limites deste mundo restrito marcam o território no qual os muitos vínculos que prendem as pessoas são continuamente reproduzidos através de uma densa teia de dependências. A itinerância, a iniciação precoce ao trabalho, a organização familiar da vida profissional, a solidão das companhias, a quase inexistência de laços com a sociedade mais vasta em que vivem (e da qual sentem não fazer parte), acentuam de uma forma decisiva a natureza insular desta comunidade, encerrando as pessoas num pequeno mundo do qual dificilmente conseguem sair.

\section{Bibliografia}

Afonso, J.; Antunes, M. J. L. 1999. Estudo de viabilidade de propostas educativas para a população circense. Lisboa, Edição do Ministério da Educação. Coleç̧ão CLAIM/ED.

Afonso, J.; Antunes, M. J. L. 2000. Empresários, artistas e empregados: estrutura e recomposição social no circo. Etnográfica, 4 (1): 89-107.

Antunes, M. J. L. 1997. Só Faz Falta Quem Cá Está: Recomposição Social numa Companhia de Circo. Tese de Mestrado em Ciências Sociais, Lisboa, Instituto de Ciências Sociais da Universidade de Lisboa.

Barth, F. 1969. Ethnic groups and boundaries. In: Barth, F. Process and form in social life. Selected essays of Fredrik Barth: Volume I. London, Routledge \& Kegan Paul: 198-227.

Bourdieu, P. 1977 (1972). Outline of a Theory of Practice. Cambrige, Cambridge University Press. 
Cabral, J. Pina; Lourenço, N. 1993. Em Terra de Tufoes. Dinâmicas da Etnicidade Macaense. Macau, Instituto Cultural de Macau.

Cabral, J. Pina 2000. A Difusão do Limiar: Margens, Hegemonias e Contradiçōes na Antropologia Contemporânea. Análise Social, XXXIV(153): 865-892.

Carmeli, Y. S. 1985. Family and economics in an English circus 1975-1979. PhD thesis, London University College, University of London.

Carmeli, Y. S. 1987. Why does the Jimmy Brown's Circus Travel? A Semiotic Approach to the Analysis of Circus Ecology. Poetics Today, 8/2:219-244.

Cohen, A. P. 1985. The Symbolic Construction of Community. London, Routledge.

Gmelch, S. B. 1986. Groups that don't want in: Gypsies and Other Artisan, Trader, and Entertainer Minorities. Annual Review of Anthropology, 15:307330.

Goffman, E. 1990 (1963). Stigma. Notes on the Management of Spoiled Identity. London, Penguin Books.

Hancock, I. 1988. Le Stéréotype du Gitan. Études Tsiganes, 3:20-25.

Hancock, I. 1997. Duty and beauty, possession and truth: lexical impoverishment as control. In: Acton, T.; Mundy, G. (ed.). Romani Culture and Gypsy Identity. Hertfordshire, University of Hertfordshire Press: 180-187.

Hotier, H. 1995. Cirque, communication, culture. Bordeaux, Presses Universitaires de Bordeaux.

Liégeois, J.-P. 1971. Les Tsiganes. Paris, Éditions du Seuil.

Liégeois, J.-P. 1989 (1985). Cigmnos e Itinerantes. Lisboa, Santa Casa da Misericórdia de Lisboa.

Machado, A. M. C. 1988. Ciganos portugais: une Marginalisation Traditionelle. Études Tsiganes, $\mathrm{n}^{\circ} 4$.

Mayall, D. 1988. Gypsy-Travellers in Nineteenth Century. Cambridge, Cambridge University Press.

Okely, J. 1993 (1983). The Traveller-Gypsies. Cambridge, Cambridge University Press. 